\title{
EMPLOYEE DECISIONS WITH RESPECT \\ TO 401(k) PLANS: EVIDENCE FROM \\ INDIVIDUAL-LEVEL DATA
}

\author{
Andrea L. Kusko \\ James M. Poterba \\ David W. Wilcox
}

Working Paper No. 4635

\section{NATIONAL BUREAU OF ECONOMIC RESEARCH \\ 1050 Massachusetts Avenue \\ Cambridge, MA 02138 \\ February 1994}

We are grateful to Richard Koski and Paul Euell of Buck Consultants for providing us with data, to Stephen Helwig for research assistance, to Regina Watson for assistance in preparing the manuscript, and to the Center for Advanced Study in Behavioral Sciences, the Federal Reserve Board, the National Institute on Aging, and the National Science Foundation for research support. Opinions are those of the authors and are not necessarily shared by the Board of Governors or the other members of its staff, or by the National Bureau of Economic Research. This paper is part of NBER's research programs in Aging and Public Economics. 
NBER Working Paper \#4635

February 1994

\title{
EMPLOYEE DECISIONS WITH RESPECT \\ TO 401(k) PLANS: EVIDENCE FROM \\ INDIVIDUAL-LEVEL, DATA
}

\begin{abstract}
401(k) plans have been the most rapidly growing type of employer-provided pension plan during the last decade. This paper utilizes employee-level data from the $401(\mathrm{k})$ plan at a medium-sized U.S. manufacturing firm to analyze the participation and contribution decisions of workers eligible for this plan. Our analysis reveals two important features of $401(\mathrm{k})$ participant behavior. First, contribution decisions of eligible employees are relatively insensitive to the rate of employer matching on worker contributions. Most employees maintain the same participation status and contribution rate year after year, despite substantial changes in the employer's match rate at the firm we study. This suggests that employer matching may not be a critical factor in explaining the growth of $401(\mathrm{k})$ plans. Second, we find that institutional constraints on contributions, imposed either by the employer or by the IRS, are an extremely important influence on contributor behavior. About three quanters of eligible employees contributed at rates that place them at one of the "comers" or "kinks" in the $401(\mathrm{k})$ opportunity set. This finding must be recognized in any analysis of how changes in $401(\mathrm{k})$ plan provisions are likely to affect contribution levels.
\end{abstract}

Andrea L. Kusko

Board of Governors of the Federal Reserve

Washington, D.C. 20551

David W. Wilcox

Board of Governors of the Federal Reserve

Washington, D.C. 20551
Jannes M. Poterba

Department of Economics

MIT, E52-350

Cambridge, MA 02139-4307

and NBER 
$401(k)$ plans have been the most rapidly growing type of employer-provided retirement saving plan during the last decade. These plans, also known as cash and deferred compensation accounts, permit individuals to defer taxes on current earnings and to earn pre-tax returns on their retirement savings. Most employers who offer $401(\mathrm{k}) \mathrm{s}$ also match at least part of their employees' contributions to these plans. In 1990 , contributions to $401(k)$ plans totalled $\$ 49$ billion, more than employer contributions to defined-benefit pension plans. The number of workers participating in these plans grew trom 4.4 million in 1983, to 20.8 million in 1990 (U.S. Department of Labor, 1993).

In spite of the popularity of $401(k)$ plans, there is no consensus on how plan characteristics, such as the employer match rate or the IRS- and employer-imposed limits on worker contributions, affect $401(k)$ contributor behavior. These issues are central to understanding the rapid growth of these plans, and also to assessing the impact of potential legislative changes on participation in these plans. Two studies that explore the relationship between $401(k)$ plan characteristics and contribution decisions are Andrews (1992) and Papke (1993). The former constructs a proxy for the employer match rate based on a question on the May 1988 CPS about whether the employer as well as the employee contributes to the $401(k)$ plan, and then uses this variable to estimate $401(k)$ contribution equations. Andrews' results suggest that employee participation rates are higher when the employer offers a matching contribution, but that contribution rates conditional on participation are lower. One less-than-fully-satisfactory aspect of the CPS data is that they include neither the rate at which employers match employee 
contributions, nor the fraction of employees for whom the employer match applies at the margin. The latter deficiency is potentially important because many employers match contributions only up to a fixed fraction of the employee's salary. Papke (1993) estimates contribution equations using data from the form 5500 that each plan must file with the IRS. She studies the relationship between the average contributions per plan member and the ratio of employer to employee contributions, the average employer match rate. She finds a positive association between average match rates and employee contributions at low match rates, but a negative relationship at match rates above 50 percent. These correlations might not represent the true behavioral response of contributions to changes in the match rate, however, if average and marginal match rates are different. For example, it could be that employers with more generous match rates set a lower cap on the fraction of employee compensation that they will match. In this case, crosssectional comparisons of $401(k)$ plans could spuriously show a negative correlation between the match rate and the amount contributed to the plan.'

There is a more general problem in interpreting cross-sectional evidence on the correlation between contribution rates and plan characteristics: self selection. If some firms institute high match rates or offer to match a high percentage of salary in order to attract workers who are interested in saving and therefore value

\footnotetext{
'Papke (1993) notes that employer contributions reported on the Form 5500 include any fat per-participant contributions made by the employer and "helper" contributions made to pass the IAS nondiscrimination tests. Such contributions offer the employee no incentive to raise his own saving at the margin.
} 
these benefits, then the observed correlation between these plan features and contribution rates may simply reflect the nature of equilibrium matching between workers and firms, not the effect of match rates on contribution decisions. Ippolito (1993) argues that precisely such self-selection explains the rapid increase in the popularity of $401(\mathrm{k}) \mathrm{s}$. He postulates that workers who value retirement saving are on average better workers than their "short-horizon" counterparts, and that by offering a $401(\mathrm{k})$ plan, an employer can attract and retain high-quality workers.

Papke (1993) is the only researcher who has considered such self-selection in her empirical analysis. She relates changes in average contributions at a set of plans to changes in match rates at the same plans, and thus controls for timeinvariant employee characteristics and plan-specific effects. The resulting estimates of the link between match rates and contributions, while less precise than her findings in the cross-section, continue to suggest a positive, then negative, association between match rates and contributions as the match rate increases. ${ }^{2}$

The present paper differs from other recent studies of $401\{k\rangle$ contributors in that it exploits panel data on the $401(\mathrm{k})$-related decisions of individuats at a single medium-sized manufacturing firm. ${ }^{3}$ Our goal is to investigate the determinants of

\footnotetext{
${ }^{2}$ If employers tend to adjust the fraction of salary that they will match at the same time that the adjust match rates, then the difficulties of interpretation noted above could apply to these results as well.

${ }^{3}$ In focusing on individual-level records from a large employer, the current paper parallels a number of recent papers on defined-benefit pension plans and retirement decisions. Examples include Kotlikoff and Wise (1987, 1989), Lumsdaine, Stock
} 
$401(\mathrm{k})$ participation and contribution rates, and the dynamics of $401(\mathrm{k})$ contributor behavior. Employee records are an excellent data source for investigating some issues relating to $401(\mathrm{k})$ plans, and a very poor data source for others. On the one hand, our use of these data insulates us from the problems of plan-specific effects and selection bias noted above. Moreover, these data provide very detailed information on the patterns of $401(k)$ contributions across age and income classes within the firm, and on how individual employees change their participation and contribution status when the plan's structure changes. On the other hand, we do not have any information on household income received from sources other than this firm, or on household assets or liabilities other than those held in the plan. This paper is divided into five sections. The first summarizes the basic structure of the $401(k)$ plan at the firm we analyze, hereafter Firm $X$, and presents summary statistics on participation and contribution rates. Section 2 examines the importance of contribution limits, both those imposed by the 401 (k) plan itself and those imposed by the IRS, in influencing contributor behavior. Section 3 presents simple tabulations showing the correlation between employee age and income and their and contribution rates, and compares these with the results in other studies that could not control for plan characteristics. The fourth section sketches the dynamics of participation and demonstrates that there is substantial inertia in 401 (k) contributor behavior. Most employees who contribute in one year also contribute in the next year, and they typically contribute the same share of salary

and Wise (1990, 1992a, 1992b), and Stock and Wise (1990a, 1990b). 
5

in both years. This finding obtains even when the employer match rate changes between years. There is a brief conclusion.

\section{An Overview of the $401(\mathrm{k})$ Plan at Firm $X$}

Our data set includes information on employee contributions to a $401(\mathrm{k})$ plan at a medium-sized manufacturing firm. In three of the four years for which we have data, the plan offered an employer match on contributions up to the first 6 percent of eligible compensation. Eligible compensation was defined as regular base compensation including some commissions but excluding bonuses and overtime. Employees were allowed to defer up to 10 percent of eligible compensation, but contributions in excess of 6 percent were not matched. The match rate was linked to the firm's profitability in a prior period. Between April 1 , 1987 and March 31,1988 , the match rate was 25 percent. It increased to 65 percent on April 1, 1988, and then to 150 percent on April 1, 1989, before declining to 139 percent on April 1, 1990 and then to zero on April 1, 1991.4 Changes in the match rate were announced a few months before they went into effect, thus allowing eligible employees ample time to adjust their participation and contribution status. There were no major changes to other features of the $401(\mathrm{k}$ ) plan during this time period. Employees could direct their contributions into an S\&P stock fund, a guaranteed income fund with a pre-determined rate of return

"Such large swings in the match rate are unusual. Papke, Petersen, and Poterba (1993) find that match rates typically exhibit strong persistence. 
(GIC), or a company stock fund. Employer contributions were all placed in an employee stock ownership plan (ESOP), and thus were invested in company stock.

Until Aprif 1989, the firm also sponsored a "thrift plan," which employees could contribute to out of after-tax income. There was no employer match for this plan, but taxes on the capital income from plan assets were deferred until the contributions were withdrawn. When both plans were in effect, contributions were capped at 10 percent of salary for each plan individually and 15 percent of salary for the two plans combined. ${ }^{5}$ The firm also provided a defined-benefit retirement plan with benefits determined by average pay over the last five years of employment.

Our data set includes annual observations on roughly 12,000 salaried and nonunion hourly employees of this firm for the years 1988 through $1991 .^{\text {O }}$ It was provided to us by Buck Consultants, a major benefits consulting firm. Of the workers eligible to participate in this plan in 1989, 8 percent were younger than 25 years of age, 58 percent were between 25 and 45,32 percent were between 45

\footnotetext{
${ }^{5}$ The elimination of the thrift plan appears not to have affected the aggregate participation and contribution rates for the $401(k)$ plan very much, in part because relatively few workers could "replace" the thrift plan by joining the $401(k)$ plan. More than 90 percent of the roughly 1500 thrift plan members in 1988 also contributed to the 401 (k) plan. Roughly three-quarters of those who were participating in both plans were already contributing enough to the $401(\mathrm{k})$ to recelve the full employer match, and many of them were at the contribution limit of 10 percent of salary. Of the 114 individuals who participated only in the thrift plan in 1988, nearly two-thirds joined the $401(k)$ in 1989.
}

'The firm's unionized hourly employees are not included in the dataset because they participated in a separate deferred compensation plan. 
and 65 , and 2 percent were over 65 . Forty-seven percent earned less than $\$ 25,000,23$ percent earned between $\$ 25,000$ and $\$ 40,000$, and the remaining 30 percent earned more than $\$ 40,000$. About 75 percent of the eligible employees were men.

Table 1 presents summary statistics on contributor behavior during the years 1988-1991. ${ }^{7}$ The overall participation rate, whether measured for the $401(\mathrm{k})$ alone (as reported in the table) or for the $401(\mathrm{k})$ and thrift plans combined, was between 78 percent and 84 percent in all four years. These participation rates are higher than those reported in most surveys of $401(\mathrm{k})$ plans. For example, Poterba, Venti, and Wise (1993) calculate from the 1991 Survey of Income and Program Participation (SIPP) that only 71 percent of workers eligible to participate in 401 (k) plans did so. The difference is even more striking because household survey repsonses are biased toward everstating the $401(k)$ contribution rate in any year. Our analysis counts only those employees making contributions to the plan in a given year as participants in that year. In some surveys, individuals may be counted as participants if they have nonzero balances in their $401(\mathrm{k})$ accounts, regardless of whether they actually make contributions in a given year.

\footnotetext{
${ }^{7}$ We measure participation and contribution rates in two ways. The rates in the upper panel are based on each employee's contributions to his 401 (k) over the course of a year, divided by that employee's "base salary," while those in the lower panel are based on the deferral percentage designated by the employee, as recorded with the plan at year-end. The two measures of overall participation are essentially the same through 1990, but diverge sharply in 1991. The mean and median contribution rates are about the same when computed using the two approaches.
} 
Despite the very substantial changes in the employer match rates over our sample period, the overall participation rate in the $401\langle k\rangle$ plan at Firm $X$ did not vary greatly from year to year. It held steady in 1989 when the match rate increased from 65 percent to 150 percent on April 1, and it declined by less than six percentage points when matching was eliminated in 1991. These results suggest a relatively small elasticity of participation with respect to the match rate, and cast substantial doubt on the view that employer matching is a key factor in explaining the rapid expansion of $401(\mathrm{k})$ plans.

One potential explanation of the small responsiveness of participation to the match rate at Firm $X$ is that the employees at Firm $X$ are accustomed to big swings in matching. Most participants are in the plan for the "long haul," and as suggested by Shefrin and Thaler (1988) and Thaler (1994), may view contributions to the $401(k)$ plan as separate from other current income flows. Another potential explanation for this insensitivity is that saving through $401(\mathrm{k})$ accounts is more attractive than saving through other channels without favorable tax treatment, so those who are saving continue to contribute to these accounts even when the match rate is zero.

The stability of the participation rate in 1989 reflects two offsetting factors: an increase in participation among persons who worked at Firm $X$ in 1988 but did not contribute to the 401 (k) plan, and an influx of new workers who had very low participation rates. For employees who were Firm $X$ in all four years of our data, the participation rates based on contributions during the vear were 84 percent (1988), 93 percent (1989), 92 percent (1990), and 86 percent (1991). Even for this group, the movements in participation are small. 
Swings in the match rate appear to have had a small but noticeable effect on the contribution rates of active participants. Between 1988 and 1990, the mean contribution rate rose by between $1 / 2$ and $1 / 4$ percentage point, depending on which measure of the contribution rate one uses. In 1991, when the employer match was eliminated, the increase in the mean contribution rate over the preceding three years was reversed. The median $401(k)$ contribution rate for participants held steady at 6 percent of compensation, the maximum amount eligible for the employer match, in all four years. ${ }^{9}$

Another key indicator of contributor behavior is the fraction of employees who failed to exhaust the employer match, either by not contributing at all or by contributing less than 6 percent of their salary. These employees passed up the opportunity to earn extraordinarily high returns on additional savings. For example, in 1989 these employees could have earned an immediate return of 150 percent in addition to the usual benefits of tax-free accumulation in the $401(\mathrm{k})$ plan. The fraction of employees in this category fell by about one-fifth between 1988 and 1990, the second year of the extraordinarily high match. Nonetheless, even in 1990, roughly 40 percent of employees failed to contribute the full matched amount. One possible explanation is that they were liquidity constrained. Given

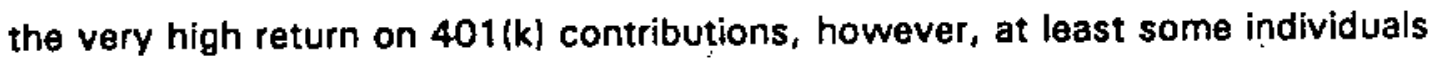

\footnotetext{
'Since the match rate at Firm $X$ is related to past profitability, changes in the match rate may be associated with changes in future firm prospects. This makes the small response to match rate changes even more striking, since employees might associate reductions in the match rate with downward revisions in their future labor earnings at the firm.
} 
close to retirement could profitably have borrowed even at credit-card interest rates and used the proceeds to increase their $401(k)$ contributions.

Even if liquidity constraints should not have been a relevant consideration for older workers, they may have been perceived as such by younger workers because employees could not withdraw plan assets before age 59-1/2 unless they terminated employment with the firm. Firm $X$ did not allow "hardship" withdrawals from the 401 (k) plan, but plan participants were allowed to borrow against their plan assets. ${ }^{10}$ Relatively few $401(k)$ participants at Firm $X$ took advantage of the loan provisions. In 1988, for example, just over 5 percent of plan members had outstanding loan balances. This suggests that once assets are placed in a $401(k)$ account, contributors are unlikely to draw them down at least so long as they remain with the current employer. This finding, if it generalizes to other firms with 401 (k) plans, suggests that contributions to these plans are likely to remain invested for long periods and therefore affect household net worth at retirement.

\section{The Importance of Centribution Limits}

The $401(k)$ plan at Firm $X$ is an attractive saving vehicle, with an after-tax rate of return that exceeds that on traditional taxable saving instruments. Precise

\footnotetext{
${ }^{10} \mathrm{~A}$ loan amount could not exceed the least of: $\$ 50,000$; half the vested amount; and 80 percent of the balance in the non-employer account. The loan rate was tled to the prime rate, with interest credited to the borrower's own account. Borrowing did not limit the employee's ability to continue making $401(k)$ contributions or affect the firm's matching contribution.
} 
delineation of the opportunity set confronted by eligible employees is complicated, however, because the marginal incentive to save depends on various plan-specific and IRS-imposed rules, and on the individual's contribution level.

At Firm $X$, an individual's contribution is limited to the smaller of 10 percent of compensation, a plan-imposed limit, or \$7000 (1987 dollars), an IRS-imposed limit. Contributions of up to 6 percent of salary are matched by the employer, while contributions of more than 6 percent are not matched." In both cases, the balance in the account accumulates at the pre-tax rate of return. ${ }^{12}$ For the typical employee, these rules induce two kinks in the budget set: one when the employer match is exhausted at 6 percent of compensation, and one when the plan's contribution limit is reached at 10 percent of compensation.

Table 2 presents evidence on the importance of the various contribution constraints at Firm X. As in Table 1, we present results based on two different measures of contribution status: the contribution rate recorded at the end of the year, and the effective annual contribution rate, caiculated by dividing dollars contributed during the year by base pay earned during the year. By either method,

\footnotetext{
${ }^{11}$ Employees at Firm $X$ who earned more than $\$ 116,667$ (1987 dollars) would have reached the IRS-imposed limit on dollars contributed $(\$ 7000)$ before exhausting the empioyer match.

${ }^{12}$ When the balance is withdrawn, taxes are due on the original contribution, the employer match, and the investment return. In addition, withdrawals made before an individual reaches age 59-1/2--for example, when he changes jobs--may be subject to a 10 percent federal penalty.
} 
the kinks and corners in the budget set appear to have played an extremely important part in determining contributor behavior.

Measured by end-of-year contribution elections, three-quarters of all employees were at one of the kinks or corners, contributing either nothing, 6 or 10 percent of pre-tax base pay, or the maximum dollar amount allowed by the IRS. Moreover, these employees accounted for more than four-fifths of all doliars contributed. Nearly $\mathbf{4 0}$ percent of all contributions came from employees contributing 6 percent of their salary; another 40 percent came from those contributing 10 percent; and another 5 percent came from those contributing the maximum dollar amount allowed by the IRS. The clustering of contributions at these points is important because changes in the employer match rate may have little or no effect on these contributions. Conversely, changes in other plan parameters, including the fraction of compensation eligible for match and the ceilings on contributions specified by the plan and the IRS, may have considerable influence on the level of $401(k)$ saving.

The results based on the effective contribution rates, shown in the last two columns of Table 2, are a bit less striking but still consistent with the assertion that the constraints were very important. By this measure, roughly half of all employees were at a kink or a corner, and 60 percent of all dollars contributed were received from such employees. 


\section{Individuat Characteristics and $401(k)$ Contribution Behavior}

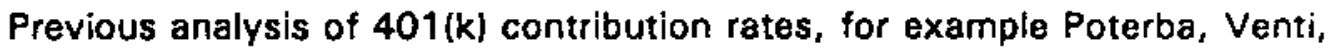
and Wise 11992, 1993), has shown that in household survey data, 401(k) participation and contribution rates are increasing functions of employee age and income. This is usually interpreted as evidence that the probability that a given individual will participate in a given plan rises with age and income. The observed pattern in cross-section household surveys, however, could arise even if this description of individual behavior were false. If, for example, the plans available to older workers tend to be more attractive than the plans for younger workers, perhaps because of differences in the types of firms that employ older and younger workers, then we might observe rising age-participation profiles even if each individual's decision was independent of age. By analyzing data from a single 401 (k) plan, we avoid the possibility that unobserved plan characteristics are confounding our interpretation of individual behavior.

Table 3 reports information on how $401(k)$ saving varied at the end of 1989 with the characteristics of indivioual employees. As suggested by previous work. participation rates (the upper panel) were greatest among higher-income workers. Fully 95 percent of those earning more than $\$ 40,000$ were recorded as making contributions to the plan, and participation among those earning between $\$ 25,000$ and $\$ 40,000$ was almost as high. Age seems to be a relatively unimportant determinant of participation for these income groups, but it does seem to have been more important among those who earned less. In the $\$ 10,000-\$ 25,000$ 
income group, workers over the age of 45 participated at roughly the same rates as upper-income employees of all ages, but younger workers were much less likely to participate. ${ }^{13}$

Consistent with the evidence from other studies, contribution rates also varied across income and age categories (the lower panell. Among workers who earned more than $\$ 10,000$, the average contribution rate was an increasing function of both income and age. Indeed, among workers who earned more than $\$ 40,000$ and were at least 45 years old, the average contribution rate was about 8 percent. On average, participants earning more than $\$ 40,000$ contributed enough to exhaust the employer match. Among workers earning $\$ 40,000$ or less, only those who were at least 45 years old contributed enough, on average, to exhaust the employer match.

\section{Dynamics of Contribution Behavior}

Our panel data afford us an unusual opportunity to examine the dynamics of individual contributions over time. In particular, they allow us to examine Papke, Petersen, and Poterba's (1993) conjecture that the high degree of persistence of participation and contribution rates at the plan level is the result of inertia in individual decisions. Table 4 examines the behavior of the 7768 employees who

\footnotetext{
${ }^{13}$ Our data suggest that 23 percent of workers with incomes below $\$ 10,000$ belonged to the plan in 1989 . Some members of this group may have worked at Firm $X$ for only part of the year and thus are showing incomes that understate their full-year earnings. Others may be part-time workers who have spouses with jobs.
} 
were on the firm's payroll in all four years of the sample. It shows that relatively few of these employees altered their participation status in either direction during this period. Moreover, those changes that did occur tended to coincide with the swings in the match rate. Notably, between 1989 and 1990, a period when the match rate was relatively stable, only about 2 percent of the sample changed its status; 98 percent of the persons who made contributions in 1989 also made contributions in 1990, and 92 percent of noncontributors in 1989 remained noncontributors in 1990 . The largest change in participation status occurred between 1988 and 1989, when the year-end match rate jumped from 65 percent to 150 percent, and 63 percent of the 1988 noncontributors joined the plan. ${ }^{14}$

A convenient way of summarizing the economic implications of the transition probabilities in Table 4 is to calculate the steady-state distribution of employees that would obtain if those transition probabilities described employee behavior forever. Straightforward calculations show that the transition probabilities for 1988-1989, when the match rate was increasing sharply, are consistent with a steady state in which $98-1 / 2$ percent of these long-term employees participate in the $\mathbf{4 0 1}(\mathrm{k})$ plan. By contrast, the probabilities for 1989 1990, when the match rate was about constant, are consistent with a steady state in which 83 percent of these employees participate in the plan. This is not much

\footnotetext{
${ }^{14}$ The elimination of the thrift plan was a small factor as well. Also, some of those who joined the $401(\mathrm{k})$ plan in 1989 may have been part-time workers who were hired in 1988 and not eligible to participate in the $401(\mathrm{k})$ plan until one year after they joined the firm.
} 
different from the average participation rate actually observed over our sample. Finally, the transition probabilities between 1990 and 1991, when the match rate was falling, are consistent with a steady-state in which only 34 percent of employees contribute to our plan.

We also tabulated the participation rate for individuals who joined the firm during our sample to explore the possibility that new hires, many of whom leave the firm after a short period, might exhibit different behavior than established employees. Not surprisingly, the participation rate among new hires was lower than that among other workers: only about $\mathbf{5 0}$ percent of this group participated, compared with an overall participation rate of about 80 percent. The participation rate among those new hires in 1989 who left the firm in 1990 was only 6-1/2 percent. This suggests that individuals may make decisions about $401(\mathrm{k})$ participation based in part on their expected longevity at the firm.

\section{Conclusion}

Our results demonstrate two important features of $401(k)$ plan participation. First, participants are heavily influenced by the various constraints on their contributions. Three-quarters of eligible employees at the firm we analyzed contributed nothing to the plan, or set their contributions equal either to the maximum amount they could contribute or to the amount at which the employer switched from matching to not matching contributions. Second, there is substantial inertia in individual $401(k)$ contribution decisions. Most workers do not 
change the fraction of their salary that they contribute to the plan from one year to the next, even when the marginal employer match rate changes from more than 100 percent to zero. In particular, we see little evidence that workers respond to increases in the employer match rate by reducing their own contribution rate, as suggested by the results of Andrews (1992) and Papke (1993).

The data from Firm $X$ also suggest that once a worker participates in a 401 (k) plan, he is unlikely to stop. This result supports the research strategy of studies such as Poterba, Venti, and Wise (1992, 1993) that have compared the wealth of households that have been eligible for 401 (k) plans for different lengths of time to draw inferences about the net effect of these plans on household net worth. Our findings of contributor inertia suggest that conditlonal on contributing when a $401(k)$ plan becomes available, a contributor is likely to contribute in most subsequent years. This suggests that years of eligibility should be strongly correlated with total contributions.

Our findings suggest that further research on the effect of employer match rates on contribution decisions must recognize the role of nonlinearities in the contribution opportunity set. The observation that most contributors are at corners or kinks on this opportunity set suggests that simple methods of calculating the elasticity of contributions with respect to the employer match rate or other parameters of the plan may yield rather unreliable answers. However, madelling the nonlinear budget set facing potential $401(k)$ contributors and applying the econometric methods described in Hausman (1985) and Moffitt (1990) is 
complicated by the fact that the budget set facing each $401(\mathrm{k})$ contributor is agedependent. The rate of return an individual earns from tax-free accumulation depends in part on the number of years until he will withdraw the funds from his $401(k)$ account. One cannot therefore combine the simple model of $401(k)$ constraints presented in this paper with simple models of individual intertemporal choice to estimate a structural model of $401(k)$ contributor behavior. 


\section{REFERENCES}

Andrews, Emily S., 1992, "The Growth and Distribution of 401 (k) Plans," in J. Turner and D. Beller, eds., Trends in Pensions 1992 (Washington: U.S. Department of Laborl.

Hausman, Jerry A., 1985, "Taxes and Labor Supply," in A. Auerbach and M.Feldstein, eds., Handbook of Public Economics. Volume 1 (Amsterdam: North Holland).

Ippolito, Richard A., 1993, "Selecting and Retaining High-Quality Workers," mimeo, Pension Benefit Guarantee Corporation, Washington, DC.

Kotlikoff, Laurence J., and David A. Wise, 1987, "The Incentive Effects of Private Pension Plans," in Z. Bodie, J. Shoven, \& D. Wise, eds., Issues in Pension Economics (Chicago: University of Chicago Press), 283-339.

, and 1989, The Wage Carrot and the Pension Stick (Kalamazoo, Michigan: W.E. Upjohn institute).

Lumsdaine, Robin L., James H. Stock, and David A. Wise, 1990, "Efficient Windows and Labor Force Reduction، " Journal of Public Economics 43, 131. 159. and .1992a, "Three Models of Retirement: Computational Complexity versus Predictive Validity," in David A. Wise, ed., Topics in the Economics of Aging (Chicago: University of Chicago Press), 21-57. , and 1992b, "Firm Pensions and Retirement: Further Firm Evidence and Model Predictive Validity." mimeo, Harvard University.

Moffitt, Robert, 1990, "The Econometrics of Kinked Budget Constraints, " Jeurnal of Economic Perspectives 4, 119-140.

Papke, Leslie, 1993, "Participation in and Contributions to 401(k) Pension Plans: Evidence from Plan Data," forthcoming, Journal of Human Resources.

, Mitchell Petersen, and James Poterba, 1993, "Did 401(k) Plans Replace Other Employer-Provided Pensions?," NBER Working Paper 4501.

Poterba, James M., Steven F. Venti, and David A. Wise, 1992, "401(k) Plans and Tax-Deferred Saving," NBER Working Paper 4181. 
and

. 1993, "Do 401(k) Plans Crowd Out Other Private Saving?" NBER Working Paper 4391.

Shefrin, Hersh M., and Richard Thaler, 1988, "The Behavioral Life-Cycle Hypothesis," Economic Inauixy 26, 609-643.

Stock, James H. and David A. Wise, 1990a, "The Pension Inducement to Retire: An Option Value Analysis," in David A. Wise, ed., Issues in the Economics of Aging (Chicago: University of Chicago Press), 205-224.

, and $1990 b$, "Pensions, the Option Value of Work and Retirement," Econometrica 58 (September), 1151-80.

Thaler, Richard, 1994, "Mental Accounts and Household Saving," American Economic Review (May).

U.S. Department of Labor, 1993, Abstract of 1990 Form 5500 Annual Reports (Washington: U.S. Department of Labor, Pension and Welfare Benefits Administration). 
TABLE 1

Participation and Contribution Rates for the 401(k) Plan at Firm X

$1988 \quad 1989 \quad 1990 \quad 1991$

Calculated from dollars contributed during the year

$\begin{array}{ccccc}\text { Participation Rate } & 82.4 \% & 82.3 \% & 83.4 \% & 78.0 \% \\ \begin{array}{l}\text { Contribution Rate } \\ \text { of Participants }\end{array} & & & & \\ \begin{array}{c}\text { Mean } \\ \text { Median }\end{array} & 5.8 & 6.0 & 6.4 & 5.8 \\ & 6.0 & 6.0 & 6.0 & 6.0\end{array}$

Fraction of employees contributing less than 6 percent

$\begin{array}{llll}52.0 & 50.3 & 44.0 & 51.8\end{array}$

Calculated from end-of-year contribution designations

Participation Rate

Contribution Rate

of Participants

$$
\text { Mean }
$$

Median

Fraction of employees contributing less than 6 percent

Memo:

Employer Match Rate Annual Average Year-End
84.0

83.8

82.6

82.3

$\begin{array}{llll}6.0 & 6.3 & 6.3 & 6.0 \\ 6.0 & 6.0 & 6.0 & 6.0\end{array}$

48.3

37.7

39.2

42.1

$\begin{array}{rrrr}55.0 & 129.0 & 142.0 & 34.7 \\ 65.0 & 150.0 & 139.0 & 0.0\end{array}$

Note: Tabulations are based on authors' calculations using data provided by Buck Consultants. The percent of employees with unused corporate match contributions is defined as the percent with contributions of less than 5-1/2 percent of salary in the data on actual contributions (top panel), and less than six percent in the calculations using data on year-end designations (bottom panel). 
TABLE 2

Distribution of Employees and Contributions by Contribution Rate, 1990

\begin{tabular}{|c|c|c|c|c|}
\hline \multirow{2}{*}{$\begin{array}{l}\text { Contribution Rate } \\
\text { (Percent of Salary) }\end{array}$} & \multicolumn{2}{|c|}{$\begin{array}{c}\text { End-of-Year } \\
\text { Contribution Election }\end{array}$} & \multicolumn{2}{|c|}{$\begin{array}{l}\text { Contributions } \\
\text { During the Year }\end{array}$} \\
\hline & Emplovees & Contributions & Employees & Contributions \\
\hline 0 & $17.4 \%$ & $2.1 \%$ & $16.6 \%$ & $0.0 \%$ \\
\hline $1-5$ & 21.8 & 9.1 & 31.6 & 17.0 \\
\hline 6 & 37.4 & 38.5 & 17.0 & 22.6 \\
\hline $7-9$ & 3.3 & 5.4 & 19.4 & 22.6 \\
\hline 10 & 18.9 & 39.4 & 14.5 & 32.8 \\
\hline IRS Maximum & 0.9 & 4.5 & 1.0 & 5.0 \\
\hline$\$$ Contribution & 0.2 & 0.9 & n.a. & n.a. \\
\hline
\end{tabular}

Note: Tabulations are based on authors' calculations using data provided by Buck Consultants. Contributions for 1990 totalled $\$ 16.7$ million, with 10,840 contributing employees. The last row shows employees who chose to specify contributions as dollar amounts (other than the IRS maximum). 
TABLE 3

Participation and Mean Contribution Rates by Age and Income, 1989

$\begin{aligned} & \text { Income } \\ & (\$ 000)\end{aligned} \quad<25 \quad 25 \cdot 45 \quad 45-65 \quad>65 \quad$ Total

PARTICIPATION RATES (percent of eligible population)

$\begin{array}{llllll}<10 & 13.8 & 28.0 & 28.7 & 7.0 & 22.9 \\ 10-25 & 62.1 & 78.4 & 85.5 & 51.7 & 78.4 \\ 25-40 & 88.8 & 85.2 & 86.8 & 85.7 & 85.9 \\ >40 & 95.6 & 94.5 & 96.6 & 90.6 & 95.3 \\ \text { TOTAL } & 45.4 & 78.4 & 85.2 & 33.8 & 82.3\end{array}$

CONTRIBUTION RATES (percent of eligible compensation)

$\begin{array}{llllll}<10 & 3.4 & 4.3 & 5.3 & 3.3 & 4.4 \\ 10-25 & 4.7 & 5.1 & 6.1 & 5.9 & 5.4 \\ 25-40 & 4.9 & 5.2 & 6.5 & 6.7 & 5.7 \\ >40 & 6.3 & 6.6 & 7.9 & 7.5 & 7.1 \\ \text { TOTAL } & 4.7 & 5.6 & 6.9 & 6.4 & 6.0\end{array}$

Notes: Tabulations are based on authors' calculations using data provided by Buck Consultants. The population for the panel on contributions is contributors li.e., the calculation is performed conditional on knowing that the individual has a positive contribution ratel. 
TABLE 4

Probabilities of Change in Contributor Status, 1988-1991

Base Year

and Status
Contribution Behavior in Next Year Contributor

\section{Contribution Status}

Contributor $(84.1 \%)$

$99.1 \%$

$0.9 \%$

Non-Contributor $(15.9 \%)$

63.0

37.0

\section{Contribution Status}

Contributor (93.4\%)

98.4

1.6

Non-Contributor $(6.6 \%)$

7.8

92.2

1990 Contribution Status

Contributor $(92.4 \%)$

92.8

7.2

Non-Contributor $(7.6 \%)$

3.7

96.3

Notes: Tabulations are based on authors' calculations using data provided by Buck Consultants. The sample population is the set of employees who were at firm all four years. Estimates of contribution status are based on dollars contributed during the year. 